\title{
Constitución y globalización: constitucionalización de espacios supranacionales
}

\author{
María Salvador Martínez \\ Profesora Titular de Derecho Constitucional \\ Universidad Nacional de Educación a Distancia
}

Recibido: 01.10 .12

Aceptado: 15.10 .12

Resumen: Presentación del número monográfico de la revista dedicado al tema «Constitución y globalización: constitucionalización de espacios supranacionales», en el que se recogen parte de los trabajos presentados al Congreso «Constitución y Globalización» celebrado en la Facultad de Derecho de la UNED.

Palabras clave: constitución, constitucionalización, globalización, integración supranacional, teoría constitucional.

Abstract: Introduction to the special issue "Constitution and globalization: constitutionalization of supranational areas». This issue contains most of the papers of the Conference "Constitution and globalization» hold at the UNED Law School.

Key words: constitution, constitutionalization, globalization, supranational integration, constitutional theory.

Este número monográfico de la Revista Estudios de Deusto está dedicado a la constitucionalización de espacios supranacionales, desde la perspectiva de las transformaciones que han sufrido el Derecho constitucional y el concepto de constitución como consecuencia de los denominados procesos de globalización. En él se recogen las ponencias y buena parte de las comunicaciones que sobre este tema se prepararon y presentaron al Congreso «Constitución y Globalización», organizado por un grupo de profesores de Derecho Constitucional del Departamento de Derecho Político de la UNED, coordinados por el prof. Ignacio Gutiérrez Gutiérrez, y que se celebró el 22 de junio de 2012 en la Facultad de Derecho de esa misma universidad. ${ }^{1}$ Conste aquí el agradecimiento a la Revista Estudios de Deusto, y especialmente a su secretario, el prof. Luis Gordillo, por ofrecer a los organizadores del Congreso la posibilidad de hacer públicos parte de los resultados del mismo en las páginas de este número monográfico.

${ }^{1}$ Como miembro del comité organizador del congreso quiero aprovechar, aunque sea en una nota a pie, para dejar constancia de mi agradecimiento a mis compañeros de organización, Ignacio Gutiérrez Gutiérrez, Fernando Reviriego Picón y Jorge Alguacil González-Aurioles; a los ponentes, «jóvenes constitucionalistas», que aceptaron la invitación a participar en el congreso; y a los numerosos profesores de diversas disciplinas que compartieron con nosotros sus investigaciones presentando una comunicación. 
El Congreso «Constitución y Globalización» se organizó como parte del desarrollo de un proyecto de investigación que tiene por objeto el análisis jurídico de las transformaciones del Derecho constitucional producidas como consecuencia de los procesos de globalización. ${ }^{2}$ No se trata de un tema excesivamente novedoso, porque dichas transformaciones empezaron a producirse hace ya un par de décadas y porque ya han sido objeto de estudio en distintos trabajos publicados hasta el momento, pero sí lo es la perspectiva desde la que este tema se aborda. Por regla general, en los trabajos publicados hasta ahora se han analizado los efectos de los procesos de globalización sobre el Derecho constitucional limitándolos a los producidos en el ámbito de los Estados nacionales; ${ }^{3}$ sin embargo, de forma paralela y simultánea, se está produciendo una proyección de los principios y elementos definitorios del Derecho constitucional sobre los nuevos espacios supranacionales producto de la globalización, que también está siendo analizada, pero con independencia del fenómeno anterior. A nuestro juicio las transformaciones constitucionales que trae consigo la globalización no son sólo las producidas en el ámbito nacional, referidas al Estado y a su Derecho constitucional, sino también las producidas a nivel supranacional, donde cada vez es posible advertir más signos de «constitucionalización» de espacios internacionales.

Estamos, por tanto, ante dos tipos de procesos de signo contrario: el primero, de influencia transformadora de los movimientos globalizadores sobre los Estados nacionales y su Derecho constitucional; el segundo, de influencia de ese Derecho constitucional sobre la definición de nuevos espacios internacionales en los que se ejercen ahora algunas funciones tradicionales de los Estados nacionales (de manera muy clara en el ámbito de la Unión Europea, pero no sólo en él). Ambos procesos deben analizarse de forma conjunta, porque no son independientes, sino que ejercen entre sí importantes influencias recíprocas; ${ }^{4} \mathrm{y}$ porque, sólo a través de este análisis conjunto, podremos comprender en toda su extensión cómo se está modificando el Derecho constitu-

${ }^{2}$ La organización de este congreso se enmarcó en el desarrollo del Proyecto de I+D del Ministerio de Ciencia e Innovación (Investigación Fundamental) «Constitución y globalización: transformaciones del Estado constitucional y constitucionalización de espacios supranacionales» (DER2009-10375).

${ }^{3}$ Entre otros, se pueden citar Cruz Villalón, P. (Coord.), Hacia la europeización de la Constitución Española. La adaptación de la Constitución Española al marco constitucional de la Unión Europea, Fundación BBVA, Bilbao, 2006; PÉrEz TremPs, P., «La constitución antes y después de Niza», Cuadernos de Derecho Público, $\mathrm{N}^{\circ} 13$, mayo-agosto 2001, p. 267-294; y ClosA, C. (Dir.), La europeización del sistema político español, Istmo, Madrid, 2001.

${ }^{4}$ En el caso concreto de los derechos fundamentales, vid. SALVAdor Martínez, M., «Influencias recíprocas entre ordenamientos en el reconocimiento y determinación del contenido de los derechos fundamentales en Europa», en Gutiérrez, I./ Presno, M. A., La inclusión de los otros: símbolos y espacios de la multiculturalidad, Comares, Granada, 2012, p. 25-49. 
cional tradicional y cuáles serán los rasgos definitorios del Derecho constitucional del siglo XXI.

La Constitución y el Derecho constitucional han nacido y se han desarrollado hasta ahora en el seno del Estado nacional soberano. De hecho, ese Estado, esto es, la forma de organización política de la sociedad que transformaba en unidad política una pluralidad de acciones, ha sido tradicionalmente el objeto de la norma constitucional, cuya función consiste precisamente en dar a ese Estado una determinada forma, la propia del Estado social y democrático de derecho. Sin embargo, el Estado nacional soberano ya no existe como lo conocíamos. Los Estados se insertan hoy en unidades supranacionales superiores a las que han cedido competencias soberanas, actúan en una red policéntrica y de estructura dinámica de diversos actores nacionales y supranacionales, que le somete a nuevos e importantes vínculos, y su poder depende hoy, en medida creciente, de coerciones fácticas y también jurídicas originadas más allá de sus fronteras que reducen su capacidad para asegurar la igual libertad y que limitan el alcance de la legitimación democrática de sus decisiones. Así las cosas, la Constitución ha perdido parte de su fuerza normativa, en la medida en que la acción del Estado no queda plenamente determinada por la Constitución cuando actúa en el marco de instituciones y procesos que superan el ámbito estatal y que se han dotado de sus propias reglas de funcionamiento, y en la medida en que los límites y posibilidades que la Constitución establece se ven desbordados por reglas internacionales que imponen traspasar aquéllos o que niegan el uso de éstas.

Pero al mismo tiempo, y precisamente porque han ido apareciendo actores supra e internacionales dotados de un poder público que podemos calificar de «paraconstitucional», se plantea el reto de construir una red de principios constitucionales que se proyecten sobre ellos. No se trata de abandonar el Derecho constitucional apoyado en las Constituciones de los Estados, sino de proyectar sus elementos esenciales a aquellos ámbitos en los que ahora se ejercen competencias soberanas y se condiciona la actuación de los Estados nacionales. Si existen en esos ámbitos organizaciones internacionales que ejercen un poder político institucionalizado de forma similar a como lo ejerce un Estado, entonces es posible, y necesario, someterlas a un orden jurídico que cumpla, aunque de forma fragmentaria, las mismas funciones que el orden constitucional nacional. De este modo, además, esos elementos constitucionales vincularían a la organización internacional y, a través de ella, también a los Estados nacionales, reforzándose así la Constitución nacional cuya fuerza normativa se ha visto limitada. ${ }^{5}$

Es evidente que no es posible hablar hoy de una «Constitución» de la Comunidad internacional en singular, en el sentido de un código normativo

${ }^{5}$ Gutiérrez, I., «De la Constitución del Estado al Derecho Constitucional para la Comunidad internacional», Peters, A./ AZnAR, M. J., GutiÉRrez, I., La constitucionalización de la comunidad internacional, Tirant lo Blanch, Valencia, 2010, p. 15-91. 
que determine con carácter exhaustivo el fundamento, la organización y los límites del poder público que se ejerce en tal ámbito, como se hace en el nivel nacional, pero quizá sí se pudiera hablar de un «Derecho constitucional» para la Comunidad internacional integrado por elementos que quepa identificar como constitucionales, ya sea por su forma (supremacía) o por su contenido (garantía de los derechos, estructura organizativa), y que, en este sentido, puedan ser interpretados conforme a la tradición propia del Derecho constitucional. $^{6}$

Pensemos, por ejemplo, en los procesos de carácter «cuasiconstitucional» que se han desarrollado en alguna organización supranacional, especialmente en la Unión Europea, en la que se intentó una reforma de los Tratados entendida como actuación de un poder constituyente europeo, y en la que se han proyectado numerosas garantías constitucionales internas. En materia de organización se pueden ver proyectados los elementos esenciales del derecho electoral y parlamentario nacional en el derecho europeo, así como otros muchos elementos de organización interna de los Estados. Finalmente, en materia de derechos fundamentales, ya casi podemos hablar de un derecho internacional común, tanto en lo que a la dogmática general de los derechos se refiere, como al reconocimiento y contenido de derechos fundamentales concretos.

De este modo, ese «Derecho constitucional para la Comunidad internacional», parcial y fragmentario, vendría a complementar al Derecho constitucional estatal, cuya fuerza normativa se ha visto erosionada. ${ }^{7}$ Este último seguirá siendo, desde luego, el derecho que constituye a los Estados nacionales -que continuarán existiendo, aunque con rasgos diferentes a los que hemos conocido hasta ahora, y con un grado relevante de integración en organizaciones internacionales-, $y$, también, será, en buena medida, el derecho que constituya a esas organizaciones internacionales -cuya base siguen siendo los Estados nacionales-. Todo ello, obviamente, implica modificaciones en el objeto, alcance y sentido del concepto de Constitución, que quizá tendrá que construirse en adelante, no a partir de un código de origen estatal, sino de elementos situados en ámbitos jurídicos diferentes y entrelazados por relaciones complejas. ${ }^{8}$ El reto, en todo caso, es dotarse de un concepto operativo que haga justicia tanto al legado histórico que la palabra condensa como a las profundas transformaciones que hoy experimentan las realidades políticas y los sistemas jurídicos.

${ }^{6}$ Ibid.

${ }^{7}$ Vid. el interesante trabajo de PETERs, A., «Constitucionalismo compensatorio: las funciones y el potencial de las normas y estructuras internacionales», PETERS, A./ AzNAR, M. J., GUTIÉRREZ, I., La constitucionalización de la comunidad internacional, op. cit., p. 208261.

${ }^{8}$ En esta línea, Bustos Gisbert, R., La Constitución red: un estudio sobre supraestatalidad y constitución, IVAP, Vitoria, 2005. 
La tarea que acabamos de proponer incumbe no sólo a los constitucionalistas, sino también y especialmente a todos los iuspublicistas, así como a los profesores de Filosofía del Derecho, de Historia del Derecho y de otras ramas jurídicas. Reflejo de ello es el contenido de este número monográfico en el que participan profesores de diversas especialidades, que, con sus trabajos, han tratado de contribuir a avanzar en el objetivo de la construcción de un nuevo Derecho constitucional para una sociedad globalizada. 